\title{
LOS PRIMEROS TEXTOS DE PEDRO ANTONIO DE ALARCON
}

\author{
Miguel Nieto Nuño
}

Las cortas noticias sobre los inicios de Pedro Antonio de Alarcón en el oficio de escritor que nos han llegado proceden del mismo autor, y se hallan recogidas en el volumen de sus Obras Completas (Madrid, Fax, 1943). Allí, en una Historia de mis libros, por él firmada, reconocía haber comenzado a escribir a los diez años de edad, y que todas sus obras de mocedad, hasta cumplidos los diecinueve años, acabaron en el fuego. Precediendo estas declaraciones de Alarcón, Luis Martínez Kleiser, en su Comento preliminar: don Pedro Antonio de Alarcón, un viaje por el interior de su alma y a lo largo de su vida, citaba otras afirmaciones suyas extraídas de un cuadernillo autógrafo, de cuyo paradero nunca se ha sabido.

Por estas afirmaciones podemos conocer los títulos de los primeros dramas que el escritor en ciernes había puesto sobre los escenarios guadijeños, dramas que a buen seguro debieron correr el mismo destino que sus restantes escritos de aquella primera época. Cerrando esta noticia, y el volumen referido que las contiene, Mariano Catalina ofrecía una demorada relación del primer paso de nuestro autor por las imprentas. Sucedió esto en Cádiz, en un periódico del que Catalina hace creador y director a Alarcón, llamado El Eco de Occidente. En este semanario de literatura, ciencias y artes -así reza el titular del periódico y así lo recoge Catalina- afirma éste que por vez primera se publicaron trabajos de nuestro autor, con el tiempo vueltos a imprimir en otros lugares. Poco más añadía el biógrafo de Alarcón, salvo que el propietario del periódico cedió a éste y a su compañero de fatigas literarias -que se nombra más adelante- el producto de las suscripciones en la provincia de Granada, una vez amortizados los gastos de inversión.

Y poco más se ha sumado desde entonces al conocimiento de los primeros ejercicios de Alarcón como publicista y escritor. En su recopilación de Obras Olvidadas, resumía DeCoster esta misma noticia -que se viene repitiendo en las pocas ediciones críticas de nuestro autor-, y confesaba: "no he podido encontrar ejemplares de El Eco de Occidente publicados en Cádiz, aunque fueron anunciados en venta en un volumen encuadernado", ${ }^{1}$ indicando en nota a pie de página los lugares donde habían fracasado sus pesquisas: hemerotecas de Granada, Cádiz y Sevilla, bibliotecas universitarias de Granada y Sevilla,

1.- Decoster, Cyrus: Pedro Antonio de Alarcón. Obras Olvidadas, Madrid, Porrúa, 1984, pág. 4. 
Biblioteca de Temas Gaditanos, en Cádiz. A éstas podrían añadirse las hemerotecas nacional y municipal de Madrid, o la de Toledo, donde el periódico había alcanzado cierta difusión, según lo proclamaba en sus mismas páginas.

Sin embargo, un reciente catálogo de la prensa gaditana recogía la existencia del referido semanario, dudando en señalar a Alarcón como su director. ${ }^{2}$ Y lo cierto es que la hemeroteca municipal de Cádiz conserva un ejemplar suelto de los diez primeros números de este periódico, no todos íntegros. El primer número de El Eco del Occidente. Periódico de ciencias, literatura y bellas artes salió al público el domingo primero de agosto de 1852, y los números conservados confirman el mantenimiento de una periodicidad semanal hasta el 3 de octubre de aquel año, siempre en domingo. La suscripción, que debía hacerse en la redacción, calle de Cobos, número 255, montaba 4 reales en Cádiz, uno más fuera de la ciudad. Constaba el papel de ocho páginas a dos columnas en folio. Se imprimía en la oficina de Francisco Pantoja, Calle del Laurel, 129. Los dos primeros números, en última página y sobre pie de imprenta, anunciaban la venta de las obras de Manuel María Hazañas.

En verdad parece éste, y no Alarcón, como afirmaba Catalina ${ }^{3}$, el inspirador y director del semanario gaditano. Suya es la presentación del periódico, a la que dedica las cinco primeras columnas del primer número. En ella establece el carácter de la publicación: "yo me apartaré de aquellas cuyos aromáticos olores embalsamen con la política la atmósfera que respiramos, saludando sólo a las ciencias, artes y literatura, para hacerme digno merecedor de la alta honra de que la belleza compense con una dulce y espresiva mirada el fruto de las tareas que presente á su alhagüeña é interesante consideración"; y establece asímismo el público al que se dirige, con expresa finalidad: "Tales publicaciones, al par que recreativas, gratas y entretenidas, son muy útiles, porque hijas del estudio, aficionan á él, despiertan un noble entusiasmo á la juventud, hacen de moda la literatura, engendran un poderoso estímulo y brindan una ilustración fácil al BELLO SEXO". Y a continuación presentaba a los colaboradores de El Eco del Occidente: "Como quiera que para amenizar esta publicación tenga necesidad de bien cortadas plumas, cuento con mis apreciables y jóvenes amigos don Torcuato de Tarrago, don Gumersindo García Varela, don José Ramírez Aguilera y don Pedro Antonio de Alarcón, conocidos en el mundo literario, y cuyos individuos forman parte de la biblioteca española, de la que tuve alta honra de ser director y presidente".

Así pues, el mecenas gaditano nunca nombrado parece haber sido el periodista malagueño Manuel María Hazañas, que llegó a ser, según Ossorio y Bernard, Director General de Loterías, y fundó en Madrid, en 1860, el periódico La Verdad, donde volvió a

\footnotetext{
2.- Prensa gaditana (1763-1936), por Alberto Ramos Santana, et. al., Cádiz, Diputación, Ayuntamiento, Quinto Centenario, s.f. El asiento de El Eco de Occidente, en la pág. 50.

3.- "Concibió [Alarcón] pues, la idea de fundar en Cádiz una revista literaria que debía escribirse en Guadix; púsolo en conocimiento de Tárrago, y ambos de acuerdo, convinieron con el Mecenas gaditano en dar todo el original que se necesitaba para el periódico, con tal de que él se comprometiera a sufragar los gastos y contribuir con los elementos materiales necesarios para la empresa" ("Biografía de D. Pedro Antonio de Alarcón", en Obras Completas, op. cit., pág. 1901).
} 
reunir las plumas de Tárrago y Alarcón, con la suya ${ }^{4}$. Una breve alusión de Alarcón que se lee en la sexta página del número cinco (29 de agosto) de El Eco del Occidente puede interpretarse en el mismo sentido ${ }^{5}$. De todos los citados, son estos tres los nombres que ocupan los mayores espacios en los primeros números del semanario. En el de presentación que venimos citando, se incluyen dos textos de Tárrago -una leyenda en octavas reales: $E l$ puente del diablo, y un cuento titulado Un músico mayor, continuados ambos en siguientes números- que se extienden hasta la séptima página. Al final de la primera columna de ésta entra la colaboración de Alarcón, que cierra prácticamente el número.

Se trata, pues, del primer texto impreso de Pedro Antonio de Alarcón, completamente olvidado y dado por perdido. Consiste en una composición de veintisiete redondillas, que lleva por título: Introducción á un poema, y se acompaña de una nota a pie de página donde se aclara que "este poema, que no tendrá título, verá la luz pública luego que su autor piense el argumento". De tales anuncios no cabe esperar elevación poética, ni virtudes literarias de importancia. Sin embargo podemos tenerlos por significativos para comprender no ya cómo Alarcón se fue orientando en sus primeros tanteos literarios -a dos años de su gran momento creativo, según Fernández Montesinos ${ }^{6}$-, sino también cómo fueron cambiando los rumbos estéticos en los autores que empezaron a asomar mediado el gran siglo romántico.

Así, el poema comienza deshaciendo uno de los grandes motivos que inspiró a aquel movimiento, pues enajenaba de toda trascendencia poética el asunto poético del recuerdo -título de uno de los poemas más significativos de Hölderlin-, con versos formal y sustancialmente irreverentes, y rebajaba también el pedestal de la creación poética poniéndolo a nivel de comunicación periodística, como venía haciendo Campoamor:

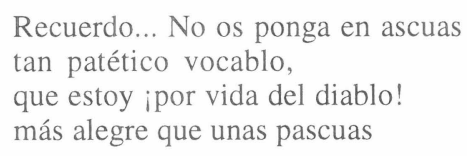

Consecuente con este arranque literario, se ajustaba Alarcón sus propias cuentas poéticas, calificando sus versos adolescentes de perversos, y prolongando con mayor acerbidad su juicio en los siguientes versos:

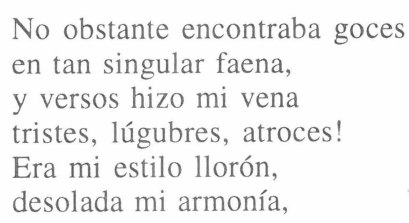

4.- Ossorio y Bernard, Manuel: Ensayo de un catálogo de periodistas españoles del siglo XIX, Madrid, Imprenta de J. Palacios, 1903.

5. Se trata de los siguientes versos:

Y es el caso... (¡vive Dios!

¡Hazañas me va á mondar!

6.- Fernández Montesinos, José: Pedro Antonio de Alarcón, Madrid, Castalia, 1977, pág. 111. 
crepuscular mi poesía,

doliente mi inspiración:

Y á las flores y á los ríos, y á las brisas y á los truenos dediqué versos tan buenos como pueden ser los míos ¡A cualquier cosa cantaba! ¡Todo era grande á mis ojos! ¡Yo hallaba placer ó enojos en todo lo que miraba!... $\mathrm{Y}$ el acento melenudo de mi ronca fantasía, si á un perro hablaba, decía: salve ¡oh can! yo te saludo! Tan valiente entonación murió en fúnebres lamentos, como á los truenos violentos se sucede un chaparrón.

$\mathrm{Y}$ envuelto en las ilusiones de la aurora de la vida, con honda pena... fingida, lloré amargas decepciones. Embarcado en mi existencia, fuí por el mar de mi llanto, queriendo helar con mi canto y asombrar con mi presencia. Por manera que el resúmen de la historia de mi lira, es énfasis y mentira, mucha voz y poco númen.

No son versos que por su calidad merezcan, ciertamente, figurar en ninguna antología de poesía decimonónica -en ellas se olvida generalmente a nuestro autor, pese a su vocación de poeta y a sus composiciones- pero sí parecen significativos para comprender los fundamentos estéticos de Alarcón, y también, lateralmente, la transición poética del Romanticismo. Si hubiéramos de escoger textos de la época que revelaran el agotamiento del primer movimiento romántico y el afán de escritores noveles por perfilar distintas actitudes estéticas, éste de Alarcón serviría notablemente a tal fin, y en esto radica su principal valor histórico. Por otra parte, juicios tan severos repetía nuestro autor al recoger en volumen sus poesías, lamentándose de su engañosa capacidad para versificar ${ }^{7}$, lo que refrenda la sinceridad de estos exámenes juveniles.

De conceder alguna razón a las afirmaciones de Catalina, no parece que Alarcón hubiera podido reunir mucho material literario con que mantener a los lectores del semanario

7.- "Habíame convencido de que, entre ser poeta con toda el alma (como yo lo era por sensibilidad y entusiasmo del corazón y de la mente) y ser cantor en verso, con la entonación, el ritmo, y la necesaria sublimidad de formas, hay esencialísimas diferencias, y de que mi propia excesiva facilidad para explicarme en tal o cual metro distaba mucho del verdadero canto..." (Obras Completas, "Historia de mis libros", pág. 5.) 
gaditano, y que sus primeros pasos públicos se encaminaban antes a destruir un pasado oscuro que a servirse de él. A las páginas de El Eco del Occidente asomaba, pues, un escritor con más ganas de hacerse que de mostrarse, casi improvisado y sin obra que considerase digna de defender ante el público.

Por esta razón, su presencia en los primeros números es escasa. Sólo a partir del tercero -en el segundo no se incluye su firma- puede tenerse en consideración. Abriendo este número se halla el único texto de Alarcón que de aquella época se ha conservado. Se titulaba Sobre el descubrimiento y paso del Cabo de Buena Esperanza, y fue incorporado luego, con un ligero cambio en el título, a la serie de Historietas Nacionales. Según su autor hubo de componerlo a la edad de quince años, y editarlo a los diecisiete o dieciocho años -Montesinos confiesa ignorar dónde ${ }^{8}$-, para volver luego a la imprenta de El Museo en 1857. La narración histórica ocupa las primeras cinco columnas y media de dicho número, y las dos primeras páginas de los tres siguientes. Por tanto, si no en los dos primeros, sí en los siguientes consiguió el novelista guadijeño encaramarse a los lugares de mayor preminencia en El Eco del Occidente.

Las variantes entre la primera redacción de Sobre el descubrimiento... y la definitiva son tantas, como suponía acertadamente Montesinos, que bien puede tenerse a la segunda como una reelaboración de la publicada en el semanario gaditano. Comenzaba aquí Alarcón con tan juvenil como destemplado juicio a la Historia por ignorar a los genios -los grandes agitadores, escribe, mencionando a mártires como Galileo o Savoranola-, todo ello impregnado de romanticismo hugoniano: "¡Loor eterno al genio, al verdadero genio, á esa epopeya de dolor que asoma en todas las épocas, á esa antorcha divina que lucha eternamente por brillar bajo el pie estúpido que quiere apagarla, á ese sacro númen, siempre aislado, perseguido, estrañado, desheredado, escarnecido por sus contemporáneos, y que sólo reina en la posteridad!".

Estas palabras servían para introducir históricamente la figura de Vasco de Gama. La larga y digresiva introducción quedó suprimida en la redacción definitiva, resumiendo tanta fogosa defensa del genio incomprendido en una justificación final de propósitos: "hacer justicia a los humildes: redimir del olvido a algunos héroes oscuros: rebajar la importancia monopolizadora de ciertos nombres, o levantar hasta ellos el nivel de toda una generación, y que no les cedía en fe, tenacidad y denuedo: tal es el espíritu que nos anima". ${ }^{9}$

Los apartados segundo y tercero de Sobre el descubrimiento... sufrieron también modificaciones en la redacción definitiva hasta tal punto, que los de El Eco del Occidente parecen apenas reconocibles en la versión posterior. El quinto de ésta recoge casi literales párrafos del cuarto apartado de El Eco del Occidente. Esta relación textual continúa en los apartados siguientes, si bien la narración primera se alarga en una conclusión -noveno apartado-, que no quiso Alarcón mantener en la redacción última, quizá porque la teoría que en ella aventuraba, que las tierras de Egipto y del Istmo centroamericano se anegarían de

8.- En op. cit. pág. 28

9.- Cito por Obras Completas, pág. 184. 
construirse respectivos canales, había perdido toda posibilidad de defensa con el paso de los años.

El cuarto número de El Eco del Occidente debió parecerle al joven Alarcón algo muy semejante a una consagración literaria, pues prácticamente todo el cuaderno lo componen escritos suyos. El ejemplar conservado se halla incompleto, faltándole las páginas cuatro, cinco y ocho. Las dos primeras se dedican a la narración histórica del Descubrimiento..., y las tres últimas, si no cuatro, se llenan también con la pluma de nuestro autor. La quinta y sexta contienen un poema de más de diez estrofas en octavillas agudas, molde formal nada extraño al Romanticismo, con las que revelaba Alarcón sus deudas literarias, su empeño por remedar las modas poéticas vigentes. El asunto, igualmente romántico, se centra en la mujer inaccesible, con generalizaciones como éstas:

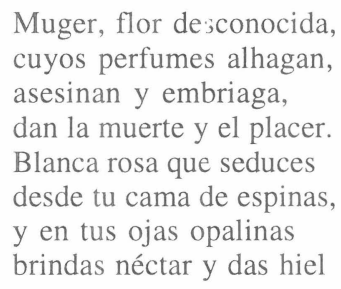

No pasaron estas estrofas a la recopilación hecha por el mismo Alarcón en 1870, como no han podido leerse nunca más las reflexiones con que, bajo el rótulo de filosóficas, concluía aquel número cuatro. Llevan por título La soledad y el poeta, y de ellas podemos obtener el retrato interior más fidedigno de aquel Alarcón de diecinueve años, reducido en Guadix, y con sueños de gran autor:

"Estas impresiones de dolor, de poesía, de meditación, tan desconocidas para el que vive en grandes capitales, son el incesante afán del pobre poeta relegado en un pueblo de provincia, ó del genio encadenado en la soledad.

En la corte, por ejemplo, la sociedad ocupa el alma, las horas, la vida del literato, que nunca tiene ocasión de pensar en su destino, de analizar sus sensaciones, de pesar sus facultades: allí nada más que el vértigo, la variedad, las emociones rápidas, la gloria, la orgía, los pensamientos instantáneos, las amistades de un momento, la moda, las necesidades ficticias, en una palabra, la comedia de la vida tal como él la ha compuesto. En el campo ó en las poblaciones pequeñas, no halla el alma pensadora diques ni distracciones en sus vuelos: la soledad, el silencio, la naturaleza, á que se encuentra más unido, le brindan desiertos á su meditación, inmensidades á su desvarío, y abismos insondables á una filosofía contemplativa, anhelosa y desesperada, consecuencia infalible de tal alma y tal existencia".

Este perfil en negativo, donde los deseos aparecen reprimidos y las circunstancias presentes, por más que insatisfactorias, sublimadas, se refuerza a continuación con cuantos precedentes literarios podía aducir el novel escritor como modelos de propia hechura, desde orígenes inciertos, y como modelos poéticos -no cabe olvidarlo- también: entre otros nombra a Byron, Zorrilla, Lammenais, Chateaubriand, pero sobre todo a Balzac, junto con 
héroes de ficción y títulos de obras como Fausto, Don Juan, El Diablo Mundo, o La Piel de Zapa. Lamentablemente falta la última hoja de este ejemplar, por lo que quedamos privados de las últimas ideas del Alarcón juvenil en torno a la soledad y la poesía. Sin embargo, el número nueve de El Eco del Occidente -26 de setiembre (sic) de 1852- trae en sus páginas cuatro y cinco una "Aclaración Importante", firmada por nuestro autor, que tiene por referencia el anterior artículo, y cuyo desarrollo sigue en correlativas "estancias" -como dice el mismo Alarcón, que las hace al estilo traspirenaico-, siete en total.

En este nuevo trabajo tampoco puede evitar Alarcón desprenderse de sus condiciones inmediatas para elevarse al nivel teórico que persigue. Pero ha modificado el registro de su pluma. Ahora, como antes en verso, se parodia a sí mismo, a sus exaltaciones románticas, a ese personaje literario interior que perseguía emularse con Espronceda, teniendo por espejo de su figura al público semanal del periódico, ante el cual los campos agotados de la inspiración se tornan ingeniosos artificios por donde la realidad, al decir de Fernández Montesinos ${ }^{10}$, comienza a mostrarse, desplazando al sueño. Todavía no conocía nuestro autor el estilo Karr, pero podemos entender por estas muestras juveniles que había en él una tendencia literaria semejante ya anunciada. La adopción de este modelo literario encuentra aquí, pues, una temprana predisposición. Las líneas que siguen sirven para completar la imagen de este autor en sus inicios, haciéndose con los solos materiales del desconcierto y la contradicción:

"Es decir, que me apodero de la cabeza inflamable de un jóven que nace en la soledad (no que vuelve á ella); que se alimenta con la lectura y la ambición de ir á la corte (no con el remordimiento); que no puede salir de su retiro; que apura todos los encantos que le rodean y se hastía de ellos; que respira, permítaseme esta frase, todo el aire de su prisión, y se ahoga por falta de ambiente; que quizás amó y fué engañado por alguna zagala de su aldea, y ya no cree en el amor; que ha tenido á la mar, al torrente, á las brisas y á las flores por testigos importunos de sus impotentes deseos, y ódia la naturaleza; que se ha hecho uraño, infatuado en su ambicion, y desconoce la amistad; que se reconcentra en sí mismo y seca cn la fiebre de sus pensamientos todas las flores de sus ilusiones, todos los jugos generosos de su alma; que vive con una velocidad prodigiosa; finalmente: que se hace pensador prematuro, misántropo precoz, engendro deforme de la ambición y la soledad, del deseo y de la impotencia, del orgullo y de la falta de siete reales diarios!

¡Ya veis si la cuestion mengua de estatura!

Estos dolores serán quiméricos; pero duelen: ha dicho un fisiólogo hábil, que todo dolor, ya proceda del pensamiento, ya proceda del corazón, es un dolor".

La sexta "estancia" de esta "Aclaración" traía citas de Byron, Larra y Espronceda, en afán de relacionar la soledad artística con el suicidio y una armónica visión ultraterrena en que culmina la séptima "estancia". Concluía el artículo afirmando que "cuando escribí el artículo

10. - Op. cit., pág. 46 
La Soledad y el Poeta no fué mi ánimo zapar las bases de la religión cristiana, ni mucho menos hacer la apoteosis del suicidio", haciendo, además, profesión de amor a la religión católica. Poco más adelante, en el mismo número, incluía Alarcón otro esquemático artículo, titulado Orígen de algunos sábios, que venía a consolar su estado de arrinconamiento en Guadix: grandes celebridades -de la literatura del momento citaba tan sólo a Balzac ${ }^{11}$ - se habían proyectado, desde su soledad esencial, en el campo de los grandes hechos históricos. Un planteamiento ingenuo del destino romántico, en el margen literario no ya del personaje, sino del autor.

Las colaboraciones en prosa remitidas por Alarcón en estos diez primeros números de $E l$ Eco del Occidente finalizan aquí. Quizá su lectura sirva para comprender mejor la complejidad de uno de nuestros grandes novelistas del siglo XIX, cuyos cambios ideológicos han carecido siempre de una base razonablemente aceptable de explicación crítica. Las contradicciones intelectuales que estos escritos revelan nos hacen comprender mejor los lances de revolucionario juerguista y arrepentido conservador que experimentó la personalidad de Alarcón al paso de tiempos y circunstancias.

Las colaboraciones en verso fueron más numerosas. Así, el quinto número del semanario gaditano acogía sus tediosos juegos versificadores del número primero, en las páginas cinco, seis y siete. Nuevamente sincero se muestra su autor, al declarar como tema de su inspiración su irremediable fastidio -habría que recordar el fastidio universal de Meléndez Valdés-, y ceder opciones al lector:

Con que así, lector amigo,

te dejo para que escojas;

ó fastidiarte conmigo

ó volver un par de hojas.

El sexto número de El Eco del Occidente ofreció también a sus lectores versos de Alarcón. Se trata en esta ocasión de un poema de catorce estrofas, quintillas, en cada una de ellas, en acrósticos, se va repitiendo el título, ¡Adiós!. Con toda probabilidad son versos de circunstancias, dedicados a la zagala a que antes se refería, y que tienen una base autobiográfica cierta. La exaltación romántica en estrofas como las siguientes:
Ay de mí! ¡Fatal momento!
Duro el destino lo ordena
$\mathrm{Y}$ en vano aplacarlo intento...
Odioso y triste y cruento
Su aciaga voz me condena
Adios, celestial muger!
Dame un último placer...
Yréme entonces en calma!
Ofréceme que ha de ser
Siempre de mi amor tu alma!

\footnotetext{
11 .- Compárese con la memoria del mismo Alarcón: "Comencé rindiendo vasallaje a Walter Scott, Alejandro Dumas y Víctor Hugo; pero me aficioné después con mayor vehemencia a Balzac y a Jorge Sand, por hallarlos más profundos y sensibles" (Apud Montesinos, op. cit., pág. 31)
} 
sugiere la presunción de que echó mano nuestro autor de materiales rezagados, de cuya calidad aún no dudaba. Tiempo después desaparecerían definitivamente del conjunto de su producción poética.

Pero a los registros paródicos volvía, en cambio, en el octavo número, tomando el hilo de los versos publicados en el primero y quinto, en una serie de veinticinco quintillas que nada dicen, como las precedentes, aduciendo la crítica de Voltaire a La Araucana. De este modo, en el noveno número escribe Alarcón el canto tercero de su paródico poema, cuyo tono pretende elevar, tanto en la forma, para lo cual recurre a octavas reales, como en el contenido, comenzando por criticar los versos anteriores:

$$
\begin{aligned}
& \text { Ya deberemos ser algo formales; } \\
& \text { pues este metro siempre se respeta } \\
& \text { y usa tan solo en las octavas reales } \\
& \text { en épicos asuntos, el poeta. } \\
& \text { Con redondillas flojas y triviales } \\
& \text { tracé la introducción; fácil cuarteta } \\
& \text { endosé al primer canto, y al segundo } \\
& \text { las peores quintillas de este mundo. }
\end{aligned}
$$

y confesando luego la historia de tan extenso poema "fashionable" -en palabras del mismo autor-: cierto enamoramiento que inspira el primer canto, su realización en el silencio del segundo, el desengaño en el tercero que se escribe en el momento. Así, ha de relacionarse con el anterior. En él nuevamente se conjugan las contradicciones poéticas de Alarcón, pues la elevación romántica como en esta estrofa se persigue

$$
\begin{aligned}
& \text { ¿Qué ánsia tengo de amar como aquel día, } \\
& \text { en que puro, inocente y confiado, } \\
& \text { era templo dichoso el alma mía } \\
& \text { de un amor celestial é inmaculado!!... } \\
& \text { ¡Oh! ¿Qué perfume, néctar ó ambrosía, } \\
& \text { gérmen de vida, númen increado, } \\
& \text { será ese amor, sin cuya grata esencia } \\
& \text { mústia y pesada queda la existencia? }
\end{aligned}
$$

concluye con el deseo de que el poema no acabe sirviendo de liadura de especias.

Finalizan así las colaboraciones de Pedro Antonio de Alarcón en los primeros pasos de El Eco del Occidente. En el último número que conserva la hemeroteca gaditana no se halla su firma. Sin embargo, en la séptima página de este número se da por concluida la primera serie del semanario, que se tenía por muy satisfactoria, habiendo alcanzado setecientos suscriptores en Madrid, Granada, Almería, Barcelona, Valencia y Toledo; y anunciaba para el 10 de octubre una segunda serie, numerada correlativamente para poder conservarse encuadernada -como señalaba DeCoster- que habría de introducir, además, cambios en la presentación tipográfica. Para esta segunda serie, "el jóven Don Pedro Antonio de Alarcón, que con tan buenos auspicios se ha dado a conocer en la literatura, acomentiendo todos los géneros, desde la historia grave hasta la poesía pasagera; desde la profundidad filosófica hasta las galas de una fantasía audaz y ardiente, nos tiene entregados varios artículos en prosa y 
verso, de cuyo mérito juzgarán nuestros lectores", anunciaba el mismo semanario. Entre estos artículos figuraría, sin lugar a dudas, El final de Norma.

La fama de Pedro Antonio de Alarcón se extendió con la divulgación del periódico. A buen seguro su apreciación en estos primeros números no fue la que proclama $E l$ Eco del Occidente, ante compañeros de redacción entonces más consolidados, como Hazañas y Tárrago. Muchos años se llevaban éstos con nuestro autor, años que denuncian unas distintas elecciones estéticas. Frente al desmayado romanticismo de sus mentores mayores, la pluma de Alarcón contrastaba por una búsqueda de originalidad renovadora. En esa busca que el escritor emprendía a tientas ante sus lectores comenzó a hacerse el narrador realista. En la continuación del semanario gaditano cada vez se haría notar más la influencia y la maduración literaria de Alarcón, que llegó a hacerse con la propiedad del periódico. Así pues, la oportunidad brindada en El Eco del Occidente parece decisiva -aunque hasta ahora ignoradapara comprenderlo. Con ello se demuestra, una vez más, cuánta necesidad estética se debe considerar en el panorama literario del pasado siglo entre la creación literaria y el trabajo periodístico, verdadero soporte histórico en que se realza la figura del novelista granadino. 